\title{
Synthesis and biological evaluation of 4'-O-acetyl- isoxanthohumol and its analogues as antioxidant and antiproliferative agents
}

\author{
Monika Stompor ${ }^{1,2}$, Marta Świtalska ${ }^{3}$, Rafał Podgórski1,2, Łukasz Uram4, \\ David Aebisher ${ }^{5}$ and Joanna Wietrzyk ${ }^{3}$ \\ 1Faculty of Medicine, Centre for Innovative Research in Medical and Natural Sciences, University of Rzeszów, Rzeszów, Poland; ${ }^{2}$ Department of \\ Biochemistry, Faculty of Medicine, University of Rzeszów, Rzeszów, Poland; 3Hirszfeld Institute of Immunology and Experimental Therapy, Polish \\ Academy of Sciences, Department of Experimental Oncology, Wrocław, Poland; 4Faculty of Chemistry, Rzeszów University of Technology, Rz-

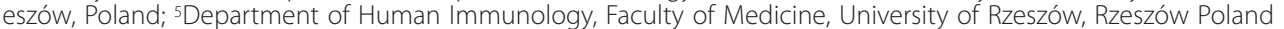

Isoxanthohumol (2) and its 4'-O-monoacylated (3) and 7,4'-O-diacetylated (4) derivatives were synthesized and evaluated in vitro for their cytotoxic activity against several cancer cell lines of various origins: MCF-7 (breast), A549 (lung), MESSA (uterine sarcoma), LoVo (colon), drug-resistant human cancer cells (MESSA/DX and LoVo/ DX), glioblastoma (U-118 MG), and also towards the non-cancerous cell line MCF-10A (normal breast cells). An antiproliferative assay indicates that 7,4'-di-O-acylisoxanthohumol (4) has similar cytotoxicity to its precursor, isoxanthohumol (2), against selected cell lines (A549, MES-SA, MES-SA/5DX, and U-118 MG). Compound 4 was only slightly more cytotoxic to lung, colon, breast (cancerous and normal) and uterine sarcoma (drug sensitive and drug resistant) cell lines compared to its monoacylated derivative (3). Both acylated isoxanthohumols showed preferential activity against tumor cells (MCF-7) and low cytotoxicity to normal cells (MCF-10A), which suggests selectivity of the acylated isoxanthohumols towards cancer cells. Additionally, the activity of the acylated isoxanthohumols was higher than for 2. To the best of our knowledge this is the first report on bioactivity of monoacylated isoxanthohumol (3) and its ester derivatives as antiproliferative compounds in drug resistant cell cultures. Acylation of $\mathbf{2}$ decreased the antioxidant activity determined by the DPPH method in the order isoxanthohumol (2) >4'-O-acetylisoxanthohumol (3) $>7,4^{\prime}$-di-O-acetylisoxanthohumol (4).

Key words: O-acylated flavanones, antiproliferative effect, isoxanthohumol, hop flavonoids

Received: 10 May, 2017; revised: 01 July, 2017; accepted: 17 July, 2017; available on-line: 12 August, 2017

e-mail: monika.stompor@gmail.com

Abbreviations: DEPT, distortionless enhancement by polarization transfer; DMPC, dimyristoylphosphatidylcholine; DMSO dimethyl sulfoxide; DPPC, dipalmitoylphosphatidylcholine; DX, doxorubicin MTT, 3-(4,5-dimethylthiazol-2-yl)-2,5-diphenyltetrazolium bromide; NMR, nuclear magnetic resonance; PBS, phosphatebuffered saline; SRB, sulfrhodamine $B$; TLC, thin layer chromatography; TMS, tetramethylsilane; HSQC, heteronuclear single quantum correlation

\section{INTRODUCTION}

Isoxanthohumol (2) is a natural aglycone flavonoid found together with xanthohumol $(1, \mathrm{XN})$ and 8-prenylnaringenin (8PN) in hop (Humulus lupulus, Cannabaceae) and in hop waste as by-products after extraction with supercritical carbon dioxide. Isoxanthohumol $(2, \mathrm{IXN})$ is also one of the three major flavonoids most abundant in beer (Stevens et al., 1999). However, during the beer-making process, 2 is obtained through thermal isomerisation of its precursor - the corresponding chalcone XN. Like many flavonoids, 2 has been found to possess numerous biological activities with potentially beneficial effects on the human body. Reported health promoting functions of 2 include antioxidant, anti-inflammatory, antibacterial, antiviral, antitumor and proestrogenic properties (Mizobuchi \& Sato, 1984; Miranda et al., 1999). Recent studies have shown that 1 can be used as an adjuvant in cancer therapy, due to its ability to increase in vivo cytostatic activity of paclitaxel, a commonly used cytostatic agent (Krajnović et al., 2016).

It is known that the biological activity of flavonoids is determined by their chemical structures and on their physicochemical properties such as size of molecules, lipophilicity and solubility (Kiekow et al., 2016; Lim et al., 2017). Many reports suggest that prenylation increases bioavailability and bioaccumulation of flavonoids and may be a promising tool for applying the biological functions of flavonoids for clinical use (Mukai et al., 2013; Terao \& Mukai, 2014; Venturelli et al., 2016). C-isoprenylated derivatives of flavonoids are potential P-glycoprotein (Pgp) modulators in tumor cells. These properties make 2 a promising and easily accessible bioactive ingredient that can potentially be applied to many nutraceutical and pharmaceutical products. However, like many flavonoids, 2 is poorly soluble in both aqueous and non-aqueous systems thus limiting its processability and application potential. Many studies have concluded that despite the fact that hop flavonoids are practically insoluble in water in their basic form and poorly bioavailable as aglycones, they possess wide range of biological activity. Hence, there have been many studies aimed at improving water-solubility of flavonoids by acylation (Saik et al., 2017). The mode of action of prenylated flavonoids is not yet fully understood. In the literature, there are only few reports describing synthesis of 2 and 8PN derivatives. To date, there are also no reports describing the chemical synthesis of mono-acylated derivatives of 2. Also, there is no information in literature about the research comparing the antioxidant and antiproliferative activity of 2 , the monoacylated and diacylated derivatives of 2, against cancer cell lines of various origin.

Keeping in mind the valuable properties of hop flavonoids, the objective of this study was to obtain 2 , its mono- and diacetate derivatives, and to investigate the 
growth inhibitory effects of these compounds on cancer cell lines of various origin. The cell lines tested include breast, lung, uterine sarcoma, colon, glioblastoma, the drug-resistant human cancer cells (MESSA/DX and $\mathrm{LoVo} / \mathrm{DX})$, and non-cancerous breast cells. We hypothesize that since antiproliferative properties of 2 have been reported, structural modifications of this compound may lead to analogs with improved growth inhibitory effects.

In this paper we report the synthesis, characterization, spectroscopic properties, antioxidant and antiproliferative activities of 4'-O-acetylisoxanthohumol (3). To the best of our knowledge, the antiproliferative activity of compounds 2-4 toward drug resistant cancer cell lines are reported here for the first time.

The described research is a continuation of our previous work on chemical synthesis of analogues of 1 and assessment of their biological activity (Stompor \& Żarowska, 2016). This study may be also helpful in utilization of by-products obtained after extraction of hop cones with supercritical carbon dioxide in the brewing industry. This waste material is rich in 1 , which we used as a substrate for the synthesis of 2 and its derivatives.

\section{MATERIALS AND METHODS}

Commercial solvents and reagents were of analytical grade. The reagents were purchased from Sigma-Aldrich Chemical Co. (Steinheim, Germany). As a raw material for isolation of 1 , by-products obtained after extraction of hops with supercritical $\mathrm{CO}_{2}$ in industrial installations located in the New Chemical Syntheses Institute, in Puławy, Poland were used. Gradient grade purity methanol was purchased from Merck (Darmstadt, Germany). 2,2-Diphenyl-1-picrylhydrazyl radical (DPPH) was purchased from Sigma-Aldrich Chemical Co. (Steinheim, Germany). Analytical thin-layer chromatography was carried out on silica gel $60 \mathrm{~F}_{254}$ plates (Merck) with chloroform:methanol $(95: 5 \mathrm{v} / \mathrm{v})$ for 1 and 2 and hexane:acetone $(5: 2 \mathrm{v} / \mathrm{v})$ as the developing solvent for derivatives of 2. Visualization of the compounds was accomplished with a solution of $10 \mathrm{~g} \mathrm{Ce}\left(\mathrm{SO}_{4}\right)_{2}$ and $20 \mathrm{~g}$ phosphomolybdic acid in $1 \mathrm{~L}$ of $10 \% \mathrm{H}_{2} \mathrm{SO}_{4}$, followed by heating. Silica gel (Kiesel 60, 230-400 mesh, Merck) was used as a stationary phase for column chromatography and a mixture of dichloromethane and methanol in different concentrations as eluents. NMR spectra $\left({ }^{1} \mathrm{H},{ }^{13} \mathrm{C}\right.$, HSQC, DEPT 135) were recorded with a Bruker $500 \mathrm{MHz}$ Ultra Shield TM Plus instrument with acetone- $d_{6}$ and chloroform- $d_{1}$ as solvents and TMS as an internal standard. High-resolution mass spectra (HRMS) were measured with a Bruker micrOTOF-Q spectrometer located in the Department of Chemistry of the University of Wrocław.

Chemical synthesis. Xanthohumol (1), the substrate for the synthesis of isoxanthohumol (2), was isolated from carbon dioxide-extracted hops. It was purified and transformed into 2 according to a modified procedure described by Wilhelm and Wessjohann (2006). Acetyl derivatives of 2 (compounds 3 and 4 ) were synthesized using different amounts of acetic anhydride in $19.7 \%$ and $54 \%$ yield, respectively. Chemical structures of the compounds were confirmed by ${ }^{1} \mathrm{H}$ and ${ }^{13} \mathrm{C}$ NMR, HSQC, IR and HR ESI-MS spectroscopy.

Chemical synthesis of isoxanthohumol (2) and its derivatives (3 and 4). Xanthohumol (1) (5.08 mmol) was dissolved in $1 \mathrm{~L}$ of $1 \% \mathrm{NaOH}$ solution and stirred at $0^{\circ} \mathrm{C}$ for $4 \mathrm{~h}$. The reaction progress was monitored by TLC using chloroform-methanol as an eluent. Acidification with $50 \% \mathrm{H}_{2} \mathrm{SO}_{4}$ gave light yellow precipitate. After filtration, the precipitate was carefully washed with water until neutral and dried. The crude product was purified by column chromatography (chloroform:methanol 95:5 $\mathrm{v} / \mathrm{v}$ ) to give 2 as a light yellow powder in 93.3\% yield. The spectral data corresponds to that described by Potaniec and coworkers (2014).

4'-O-acetylisoxanthohumol (3). The acetic acid esters of 2 , compounds 3 and 4 were prepared by the reaction of 2 with acetic anhydride in pyridine using the modified method described by Zhu and coworkers (2014).

To a solution of $2(0.2 \mathrm{~g}, 0.56 \mathrm{mmol})$ in pyridine (20 $\mathrm{mL})$, acetic anhydride $(0.07 \mathrm{~mL}, 0.56 \mathrm{mmoL})$ was added dropwise. The reaction mixture was stirred at room temperature for $24 \mathrm{~h}$, then the solvent was removed using rotary evaporation. The residue was redissolved in $\mathrm{CH}$ ${ }_{2} \mathrm{Cl}_{2}$, washed with $1 \mathrm{M} \mathrm{HCl}(3 \times 15 \mathrm{~mL})$ and then with saturated $\mathrm{NaHCO}_{3}$ solution $(15 \mathrm{~mL})$ and water to neutralize. The organic phase was separated, dried over anhydrous $\mathrm{Na}_{2} \mathrm{SO}_{4}$ and concentrated under reduced pressure. The residue was purified by column chromatography on silica gel, eluting with hexane:acetone (5:2 v/v) to give the product as light yellow crystals.

(44.1 mg, 19.7\%) ${ }^{1} \mathrm{H}$ NMR (500 $\left.\mathrm{MHz}, \mathrm{CDCl}_{3}\right) \quad \delta$ (ppm): 1.57 (s, 3H, $\mathrm{CH}_{3}-4$ "), 1.65 (s, 3H, $\mathrm{CH}_{3}-5$ "), 2.32 $\left(\mathrm{s}, 3 \mathrm{H}, \mathrm{C}-4\right.$ '-COOCH$\left.{ }_{3}\right), 2.83$ (dd, $1 \mathrm{H}, J=16.5 \mathrm{~Hz}, J=13.0$ $\mathrm{Hz}, \mathrm{CH}-3$ ), 3.03 (dd, $1 \mathrm{H}, J=16.5 \mathrm{~Hz}, J=13.0 \mathrm{~Hz}, \mathrm{CH}-$ 3), 3.18 (d, J=7.0 Hz, $\mathrm{CH}_{2}-1$ "), 3.86 (s, 3H, C-5-O$\left.\mathrm{CH}_{3}\right), 5.06\left(\mathrm{t}_{\text {sept }}, 1 \mathrm{H}, J=7.0 \mathrm{~Hz}, J=1.3 \mathrm{~Hz}, \mathrm{CH}-2\right.$ "'), 5.36 (dd, $1 \mathrm{H}, J=13.0 \mathrm{~Hz}, J=2.9 \mathrm{~Hz}, \mathrm{CH}-2), 6.28$ (s, $1 \mathrm{H}, \mathrm{CH}-$ 6), 6.87 (d, 2H, J=8.6 Hz, CH-3' and CH-5'; AA'BB'), 7.29 (d, 2H, J=8.5 Hz, CH-2' and CH-6'; AA'BB'). ${ }^{13} \mathrm{C}$ NMR $\left(125 \mathrm{MHz}, \mathrm{CDCl}_{3}\right) \delta(\mathrm{ppm}): 190.8(\mathrm{C}=\mathrm{O}), 168.8$ $\left(-\mathrm{OCOCH}_{3}\right), 162.0,159.4,156.2,154.6,132.0,130.5$, 127.7 (C-2', C-6'), 121.5 (C-2'”), 115.5 (C-3', C-5'), 115.2, 109.6, 99.1 (C-6), 78.8 (C-2’), $56.2\left(-\mathrm{OCH}_{3}\right), 45.3$ (C-3), 25.7 (C-5”), 22.9 (C-1"), $21.0\left(-\mathrm{COCH}_{3}\right), 17.7$ (C-4”). HR ESI-MS $m / z:$ 419. $1463[\mathrm{M}+\mathrm{Na}]^{+}$; calcd: 419.1465 $\left[\mathrm{C}_{23} \mathrm{H}_{24} \mathrm{O}_{6}+\mathrm{Na}\right]^{+}$.

7,4'-di-O-acetylisoxanthohumol (4). The reaction was carried out in the same way as described for compound 3, using $0.13 \mathrm{~mL}(1.4 \mathrm{mmoL})$ of acetic anhydride as the acyl group donor. The product was obtained as a white solid.

$(134 \mathrm{mg}, 54 \%){ }^{1} \mathrm{H}$ NMR (500 $\left.\mathrm{MHz}, \mathrm{CDCl}_{3}\right) \delta$ (ppm): 1.59 (s, 3H, $\mathrm{CH}_{3}-4$ ") 1.65 (s, 3H, $\mathrm{CH}_{3}-5$ "), 2.31 (s, 3H, C-4'-COOCH${ }_{3}$ ), 2.32 (s, 3H, C-7-COOCH$\left.{ }_{3}\right), 2.85$ (dd, $1 \mathrm{H}, J=16.4 J=3.1 \mathrm{~Hz}, \mathrm{CH}-3), 3.00(\mathrm{dd}, 1 \mathrm{H}, J=16.4 \mathrm{~Hz}$, $J=13.2 \mathrm{~Hz}, \mathrm{CH}-3), 3.20$ (d, 2H, J=7.0 Hz, $\mathrm{CH}_{2}-1$ "), 3.90 $\left(\mathrm{s}, 3 \mathrm{H}, \mathrm{C}-5-\mathrm{O}-\mathrm{CH}_{3}\right), 5.07\left(\mathrm{t}_{\mathrm{sep}}, 1 \mathrm{H}, J=7.0 \mathrm{~Hz}, J=1.2 \mathrm{~Hz}\right.$, CH-2"), 5.43 (dd, $1 \mathrm{H}, J=13.2 \mathrm{~Hz}, J=3.0 \mathrm{~Hz}, \mathrm{CH}-2), 6.30$ (s, $1 \mathrm{H}, \mathrm{CH}-6), 7.14$ (d, $2 \mathrm{H}, J=8.6 \mathrm{~Hz}, \mathrm{CH}-3^{\prime}$ and $\mathrm{CH}-$ 5'; AA'BB'), 7.46 (d, 2H, J=8.5 Hz, CH-2' and CH-6'; $\mathrm{AA}^{\prime} \mathrm{BB}$ '). ${ }^{13} \mathrm{C}$ NMR (125 $\left.\mathrm{MHz}, \mathrm{CDCl}_{3}\right) \delta$ (ppm): 189.9 $(\mathrm{C}=\mathrm{O}), 169.4\left(-\mathrm{OCOCH}_{3}\right), 168.7,161.6,159.4,154.6$, 150.7, 136.3, 132.0, 127.1 (C-2', C-6'), 121.9 (C-3', C-5'), 121.5 (C-2"), 115.2, 109.7, 99.3 (C-6), 78.5 (C-2), 56.2 $\left(-\mathrm{OCH}_{3}\right), 45.6(\mathrm{C}-3), 25.7$ (C-5”), 22.9 (C-1"), 21.1 (C7-COCH $\left.{ }_{3}\right), 21.0\left(\mathrm{C}-4^{\prime}-\mathrm{COCH}_{3}\right), 17.8$ (C-4'). HR ESI-MS m/ ₹: $439.1755[\mathrm{M}+\mathrm{H}]^{+}$; calcd: $439.1751\left[\mathrm{C}_{25} \mathrm{H}_{26} \mathrm{O}_{7}+\mathrm{H}\right]^{+}$.

Assay for antiproliferative activity. Cell culture and determination of $\mathbf{I C}_{50}$. Antiproliferative tests were performed on human cancer cell lines: A-549 (non-small cell lung), MCF-7 (breast), LoVo (colon), LoVo/DX (colon drug-resistant), MES-SA (uterine sarcoma), MESSA/DX5 (drug-resistant uterine sarcoma) U-118 MG (glioblastoma) and normal MCF-10A breast cell line. The cell lines were obtained from the American Type Culture Collection (Rockville, Maryland, U.S.A.) or from 
the European Collection of Authenticated Cell Cultures (MCF-7 cell line; ECACC, Salisbury, UK). The cell lines are maintained in the Institute of Immunology and Experimental Therapy, Wroclaw, Poland. The A549 and MES-SA cell lines were cultured in a mixture of RPMI 1640+Opti-MEM (1:1) (both from IIET, Wroclaw, Poland) supplemented with $2 \mathrm{mM}$ L-glutamine, 5\% fetal bovine serum (all from Sigma-Aldrich Chemie $\mathrm{GmbH}$, Steinheim, Germany). LoVo and LoVo/DX cells were cultured in the mixture of RPMI 1640+Opti-MEM (1:1), supplemented with $2 \mathrm{mM}$ L-glutamine and 5\% fetal bovine serum (all from Sigma-Aldrich Chemie $\mathrm{GmbH}$, Steinheim, Germany) adjusted to contain $1.0 \mathrm{mM}$ sodium pyruvate. MCF-7 cells were cultured in Eagle medium (IIET, Wroclaw, Poland), supplemented with 10\% fetal bovine serum, 1\% non-essential amino acid solution, $0.8 \mathrm{mg} / \mathrm{L}$ of insulin and $2 \mathrm{mM}$ L-glutamine (all from Sigma-Aldrich Chemie $\mathrm{GmbH}$, Steinheim, Germany). MCF-10A cells were cultured in the F-12 nutrient mixture (Gibco, Scotland, UK), supplemented with 5\% horse serum (Gibco, Scotland, UK), $10 \mu \mathrm{g} / \mathrm{mL}$ of cholera toxin (Vibrio cholerae), $10 \mu \mathrm{g} / \mathrm{mL}$ of hydrocortisone and $20 \mathrm{ng} / \mathrm{mL}$ of human epidermal growth factor (all from Sigma-Aldrich, Chemie GmbH, Steinheim, Germany). The LoVo/DX cell culture was supplemented with $0.1 \mu \mathrm{g} / \mathrm{mL}$ and the MES-SA/DX5 cell culture with 0.58 $\mu \mathrm{g} / \mathrm{mL}$ of doxorubicin hydrochloride (Accord Healthcare Limited, UK). All culture media were supplemented with penicillin (100 units/mL), and streptomycin (100 $\mu \mathrm{g} / \mathrm{mL}$ ) (both from Polfa Tarchomin S.A., Warsaw, Poland). U-118 MG cells were cultured in the Dulbecco's Modified Eagle's Medium (DMEM) supplemented with $10 \%$ fetal bovine serum (FBS), penicillin $(100 \mathrm{U} / \mathrm{mL})$ and streptomycin $(100 \mu \mathrm{g} / \mathrm{mL})$ solutions (all from American Type Culture Collection (ATCC, Manassas, VA, USA). All cell lines were grown at $37^{\circ} \mathrm{C}$ in a $5 \% \mathrm{CO}_{2}$ humidified atmosphere.

Antiproliferative effects of the tested compounds was examined after a $72 \mathrm{~h}$-exposure of the cultured cells to varying concentrations of the compounds tested (total plate incubation time: $96 \mathrm{~h}$ ), using the sulforhodamine B (SRB) assay for A549, MCF-7, MCF-10A, LoVo, LoVo/ Dx, MES-SA, MES-SA/DX5 cells or XTT and NR assay for glioblastoma (U-118 MG). The details of SRB technique is described by Sidoryk and coworkers (2014). The results were calculated as an $\mathrm{IC}_{50}$ (inhibitory concentration 50); the concentration of the tested agent that inhibits proliferation of the cell population by $50 \%$. IC values were calculated for each experiment separately (Nevozhay, 2014) and mean values \pm S.D. are presented in Tables 1 and 2. Each compound in each concentration was tested in triplicate in a single experiment, which was repeated 3-5 times. The activity of the tested compounds was compared to the activity of cisplatin and doxorubicin used as reference agents.

Using the obtained $\mathrm{IC}_{50}$ values, the resistance indexes (RI) for LoVo/DX and MES-SA/DX cells were calculated by dividing the $\mathrm{IC}_{50}$ values of the compounds tested against the drug-resistant cells by respective values obtained for the drug-sensitive cells. According to Harker and Sikic (1985), three categories of cells could be distinguished: (a) drug-sensitive cells - if the ratio approaches 0-2; (b) moderately drug-resistant cells - if the ratio ranges from 2 to 10 ; (c) markedly drug-resistant cells - if the ratio is higher than 10 .

Neutral Red assay (NR). Glioblastoma cells were seeded in flat bottom 96-well culture plates in triplicate at a density of $5 \times 10^{3}$ cells per well $(100 \mu \mathrm{L}$ cell suspension per well). The cells were allowed to attach for
24 h. Working solutions of 2,3 or $4(0.78-50 \mu \mathrm{M})$ were prepared in culture media with FBS from the $100 \mathrm{mM}$ stock solutions of the tested compounds in DMSO. The DMSO concentration was adjusted to $0.05 \%$ in all samples, which had no significant effect on treated cell lines (not shown). Cell monolayers were treated with working solutions of 2,3 or $4(150 \mu \mathrm{L} /$ well $)$ for $72 \mathrm{~h}$ at $37^{\circ} \mathrm{C}$. Afterwards, the media were removed and $100 \mu \mathrm{L}$ of NR solution ( $2 \%$ of the culture medium volume) was added to each well and the cells were incubated for $1 \mathrm{~h}$ in $5 \%$ $\mathrm{CO}_{2}$ at $37^{\circ} \mathrm{C}$. After washing once with PBS, $100 \mu \mathrm{L} /$ well of the fixative $\left(50 \%\right.$ ethanol, $49 \% \mathrm{H}_{2} \mathrm{O}$, and $1 \%$ glacial acetic acid) was added and the plates were shaken at 450 $\mathrm{rpm}$ for $15 \mathrm{~min}$. Absorbance was measured at $540 \mathrm{~nm}$ against $620 \mathrm{~nm}$ in a microtiter plate reader ( $\mu$ Quant BioTek, Winooski, Vermont, USA) against blank (fixative mixture). The assays were performed in triplicate in three independent experiments. Neutral red solution and 3-amino-m-dimethylamino-2-methyl-phenazine hydrochloride $(0.33 \%)$ were provided by Sigma-Aldrich Co. (Steinheim, Germany).

XTT assay. Cells were cultured as described earlier. After exposure to the tested compounds, the medium was removed and a mixture of $5 \mathrm{mM}$ of XTT and $25 \mu \mathrm{M}$ of PMS diluted three times in the complete medium was added $(100 \mu \mathrm{L} /$ well $)$ and the plates were returned to the incubator for $1 \mathrm{~h}$. Then absorbance was measured at $450 \mathrm{~nm}$ against $620 \mathrm{~nm}$ against a blank sample $(100 \mu \mathrm{L}$ of complete growth medium containing XT'T and PMS), using a microplate reader ( $\mu$ Quant - BioTek, Winooski, VT, USA). The assays were performed in triplicates in three independent experiments. XT'T sodium salt (2,3-bis[2-methoxy-4-nitro-5-sulfophenyl]-2H-tetrazolium-5-carboxanilide inner salt) and phenazine methosulfate (PMS), N-methyldibenzopyrazine methyl sulfate were provided by Sigma-Aldrich Co. (Steinheim, Germany).

Antioxidant activity. The antioxidant activity was determined by the DPPH method according to the modified procedure described by Potaniec and coworkers (2014). The absorbance was measured using a microplate reader (TECAN Infinite 200). All experiments were performed in triplicate. The radical solution was prepared by dissolving $3.94 \mathrm{mg}$ DPPH in $50 \mathrm{~mL}$ metthanol $(0.2 \mathrm{mM})$. For the photometric assay $100 \mu \mathrm{L} \mathrm{DPPH}$ solution and $100 \mu \mathrm{L}$ antioxidant solution $(0.05 \mathrm{mg}$ of compound $/ 1 \mathrm{~mL}$ methanol) were mixed. The study used the 96-well microtiter plates. After $30 \mathrm{~min}$, the absorbance was measured at $517 \mathrm{~nm}$. The antioxidant ability of the tested compound was assessed according to the following formula: \% DPPH inhibition $=100 \times\left(\mathrm{A}_{0}-\right.$ $\left.A_{c}\right) / A_{0}$ where $A_{0}$ is the absorbance of DPPH solution, $A_{c}$ is the average absorbance value of the tested solution containing antioxidant at a known concentration.

Statistical analysis. Statistical analysis showed a non-normal distribution of data in experimental groups (Shapiro-Wilk test). Therefore, to estimate the differences between 2, 3 or 4 treated and non-treated control samples a statistical analysis was performed using the nonparametric Kruskal-Wallis test. Statistical analysis was performed with Statistica 12.5 software (StatSoft).

\section{RESULTS AND DISCUSSION}

\section{Chemistry}

Based on the known biological characteristics of 2 and taking into account the antiproliferative activity of 
its precursor 1, the anticipated antiproliferative activity of the hop-derived prenylflavonoids $\mathbf{3}$ and 4 was tested on several human cancer cell lines.

The percentage content of 2 in the dry weight of the hop flowers is $0.008 \%$, however, the content of 2 in hop products, including the extract resulting from extraction with supercritical carbon dioxide, is below the detection limit (Magalhães et al., 2007). For this reason, in our research, the main hop chalcone 1 , which is a precursor of 2, was extracted from the by-product waste obtained with supercritical $\mathrm{CO}_{2}$. The spectral characteristics of the obtained substance was in agreement with literature data for 1 (Stompor et al., 2013). Next, 2 was prepared by base-catalyzed cyclization of 1 using $1 \% \mathrm{NaOH}$ at $0{ }^{\circ} \mathrm{C}$, followed by acidification of the solution with $50 \%$ $\mathrm{H}_{2} \mathrm{SO}_{4}$, to give yields up to $100 \%$.

Synthesis of monosubstituted isoxanthohumol (3) containing the acyl group at C-4' was achieved by acylation of the substrate 2 with one equivalent of acetic anhydride (Scheme 1). This reaction resulted in $19.7 \%$ conversion of substrate after $24 \mathrm{~h}$ of stirring at room temperature. The structure of the obtained product 3 was established based on the spectral data.

In the ${ }^{1} \mathrm{H}$ NMR spectrum of 4'-O-acetylisoxanthohumol (3) protons of the aromatic ring $B$ are visible as two signals, integrating for two protons each, as an AA'BB' system at $\delta=7.29\left(J_{2^{\prime},}=8.5 \mathrm{~Hz}\right)$ and $6.87 \mathrm{ppm}\left(J_{3^{\prime},}=8.6\right.$ $\mathrm{Hz})$. The only proton present in ring $A$ in compound 3 gives a singlet at $\delta=6.28 \mathrm{ppm}(\mathrm{CH}-6)$. The methylene protons of ring $\mathrm{C}$ in 3 give two signals in the shape of wide one-proton doublets of doublets at $\delta=3.03$ ppm $\left(\mathrm{H}-3_{\mathrm{ax}}\right)$ and $2.83 \mathrm{ppm}\left(\mathrm{H}-3_{\mathrm{eq}}\right)$, with coupling cons-
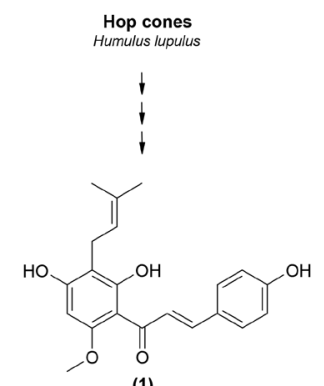

(1)

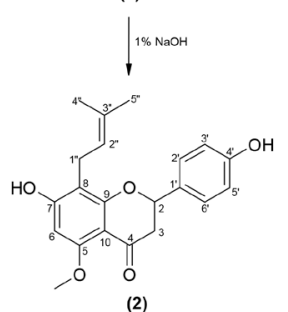

(2)
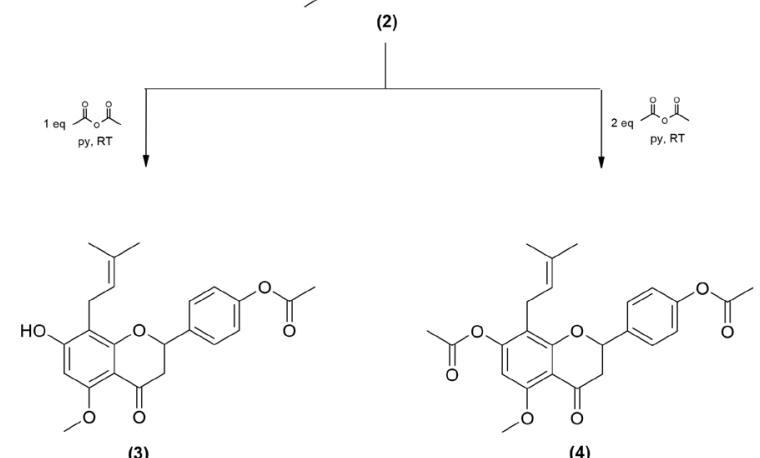

Scheme 1. Chemical synthesis of isoxanthohumol (2) and its derivatives ( 3 and 4 ). tants $J=16.4 \mathrm{~Hz}$ and $13.0 \mathrm{~Hz}$. Two three-proton singlets at $\delta=3.86$ and $\delta=2.32 \mathrm{ppm}$ indicate the presence of two alkoxy groups at C-5 and C-4' positions, respectively. A singlet of $3 \mathrm{H}$ at $\delta_{\mathrm{H}}=3.86 \mathrm{ppm}$, corresponding to the carbon atom at $\delta_{\mathrm{c}}=56.2 \mathrm{ppm}$ in the ${ }^{13} \mathrm{C} \mathrm{NMR}$ was assigned to the methoxy group, whereas the second singlet in this region $(\delta=2.32 \mathrm{ppm})$ to the alkoxy group at C-4' $(\delta=20.9 \mathrm{ppm})$. Methyl protons of the prenyl group were observed as two three-proton singlets at $\delta_{\mathrm{H}}=1.65 \mathrm{ppm}$ (H-4") and $\delta_{H}=1.59 \mathrm{ppm}$ (H-5"), which show strong correlation with the carbon atoms at $\delta_{c}=25.7 \mathrm{ppm}$ and $\delta_{\mathrm{c}}=17.8 \mathrm{ppm}$, respectively. The HR ESI-MS analysis of the pure product 3 (positive ionization mode) showed the presence of the base peak $[\mathrm{M}+\mathrm{Na}]^{+}$at $m / z 419.1465$ which suggests a monoacetate- 2 derivative. The calculated $m / z$ value for $\left[\mathrm{C}_{23} \mathrm{H}_{24} \mathrm{O}_{6}+\mathrm{Na}\right]^{+}$is 419.1465 . The structure of compound $\mathbf{3}$ was found to be 4'-O-acetylisoxanthohumol, and to the best of our knowledge, it has not been previously reported in the literature.

Treatment of 2 with two equivalents of acetic anhydride in the presence of pyridine led to 7,4'-di-O-acetoxylisoxanthohumol (4). In the ${ }^{1} \mathrm{H}$ NMR spectrum of product 4, the most shielded H-2', H-6' and H-3', H-5' protons in ring $\mathrm{B}$ were observed at $\delta=7.46$ and 7.14 ppm as two multiplets similar to a doublet, showing a typical pattern for the AA'BB' system. The presence of a methoxy group is proved by a three-proton singlet at $\delta_{\mathrm{H}}=3.90 \mathrm{ppm}$ in the ${ }^{1} \mathrm{H}$ NMR spectrum and the signal at $\delta_{\mathrm{C}}=56.2 \mathrm{ppm}$ in the ${ }^{13} \mathrm{C}$ NMR spectrum. A combined analysis of ${ }^{13} \mathrm{C}$ and DEPT $135^{\circ} \mathrm{NMR}$ indicates the presence of five primary, seven tertiary and ten quaternary carbon atoms in compound 4. Two signals of methylene groups at $\delta_{c}=22.9 \mathrm{ppm}\left(\mathrm{C}-1\right.$ ") and $\delta_{c}=45.6 \mathrm{ppm}(\mathrm{C}-3)$ were negative. In the ${ }^{1} \mathrm{H}$ NMR of 4 we observed the signals of alkoxy groups, which appeared at $\delta=2.31 \mathrm{ppm}$ and $\delta=2.32 \mathrm{ppm}$, integrating for three protons each. The HSQC spectrum showed a strong coupling correlation between the alkoxy protons and carbon atoms at $\delta_{c}=21.1$ and $\delta_{c}=21.0 \mathrm{ppm}$, respectively. High-resolution electrospray ionization mass spectral data (HR ESI-MS) of compound 4 showed the molecular ion $[\mathrm{M}+\mathrm{H}]^{+}$at $\mathrm{m} /$ z 439.1755 which established the molecular formula as $\mathrm{C}_{25} \mathrm{H}_{26} \mathrm{O}_{7}$ (calcd for $\left[\mathrm{C}_{25} \mathrm{H}_{26} \mathrm{O}_{7}+\mathrm{H}\right]^{+}$: 439.1751), demonstrating that we obtained isoxanthohumol diacetate. Compound 4 has been synthesized and is known in the literature (Aniol et al., 2012).

\section{Antiproliferative activity}

Because the biological activity of natural flavonoids and their synthetic derivatives depend on their chemical structures and on relative orientation of various moieties present in the molecule, the aim of our study was at first to obtain 2 , one of the hop flavanones, and in the next step, to synthesize two derivatives of 2 and to compare their growth inhibitory effect on cancer cell lines (MCF7, LoVo, LoVo/DX, MESSA, MESSA/DX and U-118 MG) with parent 2 . Keeping in mind that the solubility of free flavonoids is low in water and moderate in organic solvents, in our investigations comprising isolation of the polyphenol compounds from spent hops and derivatization of 2 by chemical methods we were looking for such a method of determination of antiproliferative activity that would be suitable for both hydrophilic and hydrophobic compounds. The most commonly used are MTT, NR, SBR and XTT techniques.

In our research, we used three of the above methods (XTT, NR, and SRB) based on spectrophotometric measurements involving different dyes. The XT'T technique 
Table 1. IC $C_{50}$ values $(\mu \mathrm{M})$ representing the antiproliferative activity of compounds 2-4 against human cancer cell lines determined using the SRB assay.

\begin{tabular}{|c|c|c|c|c|c|c|c|}
\hline \multirow[t]{3}{*}{ Compound } & \multicolumn{7}{|c|}{$\mathrm{IC}_{50} \pm$ S.D. $[\mu \mathrm{M}]^{\mathrm{a}}$} \\
\hline & \multicolumn{7}{|l|}{ Cell line } \\
\hline & MCF-7 & MCF-10A & A-549 & LoVo & LoVo/DX & MES-SA & MES-SA/DX5 \\
\hline 2 & $30 \pm 3.8$ & $37.1 \pm 3.8$ & $29.7 \pm 4.2$ & $8.96 \pm 1.5$ & $26.8 \pm 4.0$ & $16 \pm 3.6$ & $30.4 \pm 4.1$ \\
\hline 3 & $32.1 \pm 4.8$ & $49.6 \pm 14.5$ & $29.2 \pm 3.7$ & $11.1 \pm 4.6$ & $25.4 \pm 4.7$ & $22.1 \pm 7.9$ & $32.3 \pm 1.5$ \\
\hline 4 & $29 \pm 2.65$ & $38.7 \pm 4.4$ & $26.3 \pm 3.4$ & $9.8 \pm 3.6$ & $29.3 \pm 2.4$ & $15.7 \pm 6.9$ & $28.6 \pm 2.1$ \\
\hline cisplatin ${ }^{b}$ & $9.0 \pm 1.0$ & $9.0 \pm 1.7$ & $6.8 \pm 2.7$ & $4.9 \pm 0.7$ & $3.5 \pm 0.3$ & $1.3 \pm 0.1$ & $2.0 \pm 0.3$ \\
\hline doxorubicin b & - & - & - & $0.086 \pm 0.05$ & $6.2 \pm 2.9$ & $0.02 \pm 0.0074$ & $4.9 \pm 0.8$ \\
\hline
\end{tabular}

a Data are the means \pm S.D. of three independent experiments. ${ }^{b}$ Cisplatin and doxorubicin were employed as positive controls.

utilizes tetrazolium salts which allow an evaluation of the impact of the tested compounds on the activity of mitochondrial enzymes. The NR test utilizes neutral red, a dye which is incorporated into lysosomes of viable, uninjured cells. Lastly, we used the SRB cytotoxicity assay utilizing the dye sulforhodamine $\mathrm{B}$, which at certain $\mathrm{pH}$ values has the ability to bind electrostatically to proteins in living cells and therefore is used for cell density determination based on measurements of the cellular protein content. Because, as described earlier, anticancer effects induced by 1 towards lung cancer cells at concentrations ranging from $0.1-100 \mu \mathrm{M}$ increased at longer exposure time (Young et al., 2015), we used 72-h tests in our study.

In the first step of our study, a screening test was performed on the MCF-7 human breast cancer cell line and the MCF-10A normal cell line (Table 1). All tested compounds proved to be antiproliferative agents towards MCF-7 cancer cells, with $\mathrm{IC}_{50}<33 \mu \mathrm{M}$. At the same time, these compounds have a lower antiproliferative activity with respect to normal cells relative to MCF-10A. The solvent used (DMSO) in the highest concentration of $1 \%$ had no significant effect on cell growth (not shown).

In the next step, compounds $2, \mathbf{3}$ and 4 were tested for antiproliferative activity toward six human cancer cell lines as follows: A549 (lung), MES-SA (uterine sarcoma), LoVo (colon), doxorubicin-resistant colon cancer LoVo/ DX (P-gp-dependent, MRP-, LRP-dependent multidrug resistance), MES-SA/DX5 (P-gp-dependent resistance to doxorubicin), and also toward glioblastoma (U-118 MG).

Our results indicate that the compounds are selective in their activity towards various cell lines. According to our results, all compounds have a preference for colon (LoVo) and uterine sarcoma (MES-SA) cell lines $\left(8 \leq \mathrm{IC}_{50} \leq 22\right)$. We observed that almost all the synthesized compounds were cytotoxic to the tested cancer cell lines and that cytotoxic activity of the acyl derivatives was dependent on the position of the acyl group in the backbone of the flavone. In previous studies, diacyl derivatives of 2 showed low activity against selected human cell lines (Anioł et al., 2012). In this study, the diacyl derivative 4 showed slightly higher activity towards all newly tested cell lines, except for LoVo and LoVo/DX, compared to the monoacylated isoxanthohumol 3. This is consistent with a previous report that indicated prenylated hop flavonoids can suppress invasion and genotoxicity colon cancer cells (Caco-2) (Allsopp et al., 2013). According to these authors, the described mechanism of action appears to be independent of the estrogenic activity of these compounds.

To date, 2 was tested in vitro as a potential inhibitor of cancer cell growth toward only few human tumor lines (Hudcová et al., 2014; Miranda et al., 1999). Many results show that the determined antiproliferative activity may also depend on the method of analysis and the concentration of tested compounds. For this reason, in our study we used three independent tests: SRB, NR and XTT. $\mathrm{IC}_{50}$ values for all the prenylated compounds on tested cell lines using the SRB assay are summarized in Table 1. Table 2 presents the results obtained in two separate in vitro studies utilizing the XT'T and the NR assay in the U-118 MG cell line. Using both XTT and NR methods, compound 2 showed about 1.5-1.8-fold higher activity toward glioblastoma cells (U-118 MG) than 3 and 4 indicating that exchange of 7- and 4'-hydroxy groups on $\mathrm{A}$ and $\mathrm{B}$-rings, respectively, with $\mathrm{O}$-acetoxy groups has a considerable influence on the cytotoxicity profile (Table 2).

Similarly, slightly better results were obtained for MCF-7, A-549, MES-SA and MES-SA/DX5 cell lines. Considering the effect of hydroxyl groups on the activity of the hydroxyflavanones studied, it was observed that starting compound 2 was slightly more active than derivatives 3 and 4 towards U-118 MG cancer cells both in the NR and XTT assay. 2 was also found active against the PC-3 and DU145 human prostate cancer cells using the WST-1 assay, with the reported $\mathrm{IC}_{50}$ value of 45 and $47 \mu \mathrm{M}$, respectively (Delmulle et al., 2006).

Previous research shows that some prenylated isoflavones improve the stability of the phospholipid bilayer (Wesołowska et al., 2014). Their accumulation close to biological membranes increases membrane resistance to oxidative agents. Therefore, investigation of anticancer activity of the tested compounds requires a detailed analysis of many factors which influence this process.

It has been suggested that the biological activity of the compounds found in hops (Humulus lupulus) may be attributed to changes in nature and permeability of cell membranes. Wesołowska and coworkers (2014) and Arczewska and coworkers (2013) carried out research on major hop flavonoids 1 and 2 . The results indicate that these hop flavonoid compounds have strong affinity to biological membranes (DPPC, DMPC). It was shown that the presence of 2 in the cell membrane changes its

Table 2. $I C_{50}$ values for 2,3 and 4 after $72 \mathrm{~h}$ of treatment of U-118 MG cells. IC 50 was calculated from medians of the results obtained in the NR and XTT assays.

\begin{tabular}{lcc}
\hline Compound & $\mathrm{NR} \mathrm{IC}_{50}[\mu \mathrm{M}]$ & $\mathrm{XTT} \mathrm{IC}_{50}[\mu \mathrm{M}]$ \\
\hline 2 & 10.5 & 15.6 \\
\hline 3 & 15.4 & 27.7 \\
4 & 17.5 & 20.5 \\
\hline
\end{tabular}


Table 3. Resistance index (RI) values of compounds 2-4.

\begin{tabular}{lll}
\hline Compounds & $\mathrm{RI}^{*}$ & \\
\hline & MES-A/DX5/MES-SA & LoVo/DX/LoVo \\
\hline 2 & 1.9 & 2.99 \\
\hline 3 & 1.46 & 2.29 \\
\hline 4 & 1.82 & 2.99 \\
\hline cisplatin & 1.54 & 0.71 \\
\hline doxorubicin & 245 & 72.1 \\
\hline
\end{tabular}

conformational state in the hydrophobic region, mainly due to the strong affinity of the membrane to the prenyl group. Hydrocarbon chains of the membrane lipids change their shape and methylene group conformation, which results in a drop of the main-phase transition temperature and conversion of the membrane into the liquid-crystalline state. Among the tested flavonoids, the strongest capability of fluidization of the lipid bilayer was observed for the relatively planar, lipophilic molecule 1. Its strong affinity to phosphatidylcholine acyl chains allows deeper penetration into the lipid bilayer. Elucidation of the mechanisms of interaction between biologically active flavonoids or new synthetic derivatives with particular elements of the cytoplasmic membrane bilayer may be helpful in the design of novel therapeutic agents.

To summarize, all the compounds were moderately active antiproliferative agents and none of the modifications of 2 elicited significant changes in activity. This trend is similar to that demonstrated previously. These results confirm that new prenylated derivatives of xanthohumol have good cytotoxicity towards all tested cell lines. We observed that 2 exhibits higher activity than its esters against only few tested cell lines. After a 3-day treatment, the lowest concentration of 2 at which the growth of the cell lines was inhibited by $50 \%\left(\mathrm{IC}_{50}\right)$ was $8.96 \mu \mathrm{M}$ for colon cancer $(\mathrm{LoVO})$.

We also calculated the resistance indexes (RI) by dividing the $\mathrm{IC}_{50}$ values of the compounds tested against the drug resistant cells LoVo/DX and MES-SA/DX5 by respective values obtained against the drug sensitive LoVo and MES-SA cell lines (Table 3).

All compounds were able to overcome the barrier of P-gp-dependent resistance. Among the obtained acylated derivatives of 2 , compound 3 has the highest ability to overcome the barrier of multidrug resistance $(R I=1.46)$, which is comparable to cisplatin used as a reference $(\mathrm{RI}=1.54)$. The LoVo/DX cells showed moderate resistance $(\mathrm{RI} \leq 3)$. In all cases, the degree of resistance to the three tested flavonoids was lower than that of the established anticancer drug, doxorubicin $(R I=72)$, nevertheless they possess the potential to fight cancer multidrug resistance. Our results with cancer cell lines of various origins

Table 4. Antioxidant activity of isoxanthohumol (2) and its derivatives (3-4).

\begin{tabular}{lcc}
\hline Compound & $\mathrm{EC}_{50} \pm$ S.D. $[\mathrm{mM}]$ & $\mathrm{EC}_{50} / \mathrm{EV}_{50} \mathrm{AA}$ \\
\hline Ascorbic acid (AA) & $0.200442 \pm 0.000146$ & - \\
\hline 2 & $7.6006 \pm 0.458$ & 37.19 \\
\hline 3 & $59.701^{\mathrm{a}} \pm 8.933$ & 297.91 \\
\hline 4 & $73.4538^{\mathrm{a}} \pm 8.595$ & 366.46 \\
\hline
\end{tabular}

aExtrapolated corroborate earlier observations. Potential application of natural flavonoids in the pharmaceutical industry can be further enhanced by simple structure modifications, such as selective esterification for developing new drugs for clinical use in the future.

\section{Antioxidant activity}

Antioxidant activity shown in Table 4 is defined as a concentration of the antioxidant in $\mathrm{mmol} / \mathrm{L}(\mathrm{mM})$ that causes $50 \%$ loss of the DPPH activity $\left(\mathrm{EC}_{50}\right)$. The data are presented as mean values \pm S.D. $(n=3)$. L-Ascorbic acid was used as a positive control. In the described method a small value indicates strong antioxidant properties and therefore represents small residual unreacted DPPH in the analyzed sample. As shown in Table 4, all investigated flavanones have antioxidant activity between $73.5 \mathrm{mM}$ (very low activity) and $7.6 \mathrm{mM}$ (the highest activity, observed for 2). Ascorbic acid, a very good antioxidant, has been used as a reference standard with activity of $0.2004 \mathrm{mM}$.

Antioxidant activity depends on particular aspects of the molecular structures of the compounds. In this study we wanted to verify that the $O$-acylation of one or two of the hydroxyl groups present in 2 will not lower the antioxidant activity in comparison to the starting substrate. Our results indicate that $2\left(\mathrm{EC}_{50}=7.6 \mathrm{mM}\right)$ is about 8 -fold stronger antioxidant than its mono- (3) $\left(\mathrm{EC}_{50}=59.7 \mathrm{mM}\right)$ and 10-fold stronger than diacylderivatives (4), $\left(E_{50}=73.5 \mathrm{mM}\right)$ due to the presence of two hydroxyl groups in the molecule.

\section{CONCLUSION}

In the present study we demonstrated antiproliferative activity of flavanones 2-4 against drug-sensitive and drug-resistant cancer cell lines. For all compounds the highest activity was noted against the colon cancer cell line $\left(\mathrm{IC}_{50} \leq 11 \mu \mathrm{M}\right)$. Some compounds were most active toward uterine sarcoma (MES-SA) and glioblastoma (U$118 \mathrm{MG})$ cell lines $\left(10<\mathrm{IC}_{50} \leq 16\right)$. The highest ability to overcome the barrier of resistance $(\mathrm{RI}=1.56)$ against the drug-resistant MES-SA/DX5 cells compared to the parental drug-sensitive MES-SA cell line was found for the new compound 4'-O-acetoxyisoxanthohumol (3). Both acylated isoxanthohumols (3 and 4 ) showed higher activity against tumor cells and lower cytotoxicity against normal cells (MCF-10A) compared to 2. The antioxidant activity of the tested compounds decrease in the order: $2>3>4$. Therefore, the developed acylation protocol can be used in the synthesis of bioactive hop prenylated derivatives as potential adjuvant drugs. Such flavonoids in combination with chemotherapeutics may improve the efficacy of these agents in induction of apoptosis in cancer cells. The potential usefulness of hop prenylated flavonoids and their derivatives as interesting anticancer targets is reinforced.

For better understanding of the mechanisms involved in the action of isoxanthohumol esters as therapeutic agents, it would be interesting to characterize their activity at the molecular level. It is possible to compare their tissue distribution and subcellular localization in various cancer cell lines using the fluorescently labeled derivatives.

\section{Acknowledgements}

We would like to thank the New Chemical Syntheses Institute in Pulawy (Poland) for supplying the spent 
hops (H. lupulus L.) obtained after hop extraction by supercritical $\mathrm{CO}_{2}$.

NMR spectra were recorded in the Laboratory of Spectrometry, Faculty of Chemistry, Rzeszów University of Technology and were cofinanced from DS budget.

\section{Conflict of interest}

The authors declare that they have no competing interests.

\section{REFERENCES}

Anioł M, Świderska A, Stompor M, Żołnierczyk AK (2012) Antiproliferative activity and synthesis of 8 -prenylnaringenin derivatives by demethylation of 7-O- and 4'-O-substituted isoxanthohumols. Med Chem Res 21: 4230-4238. Doi: 10.1007/s00044-011-9967-8

Allsopp P, Possemiers S, Campbell D, Gill C, Rowland I (2013) A comparison of the anticancer properties of isoxanthohumol and 8 -prenylnaringenin using in vitro models of colon cancer. BioFactors 39: 441-447. Doi: 10.1002/biof.1084

Arczewska M, Kamiński D, Górecka E, Pociecha D, Rój E, SławińskaBrych A, Gagoś M (2013) The molecular organization of prenylated flavonoid xanthohumol in DPPC multibilayers: X-ray diffraction and FTIR spectroscopic studies. BBA Biomembranes 1828: 213-222. Doi: 10.1016/j.bbamem.2012.10.009

Delmulle L, Bellahcéne A, Dhooge W, Comhaire F, Roelens F, Huvaere K, Heyerick A, Castronovo V, De Keukeleire D (2006) Antiproliferative properties of prenylated flavonoids from hops (Humulus lupulus. L) in human prostate cancer cell lines. Phytomedicine 13: 732-734. Doi: 10.1016/j.phymed.2006.01.001

Harker WG, Sikic BI (1985) Multidrug (pleiotropic) resistance in doxorubicin-selected variants of the human sarcoma cell line MES-SA. Cancer Res 45: 4091-4096.

Hudcová T, Bryndová J, Fialová K, Fiala J, Karabín M, Jelínek L, Dostálek P (2014) Antiproliferative effects of prenylflavonoids from hops on human colon cancer cell lines. J Inst Brew 120: 225-230. Doi: 10.1002/jib.139

Inki T, Okumura K, Matsui H, Hosoya T, Kumazawa S (2017) Effect of harvest time on some in vitro functional properties of hop polyphenols. Food Chem 225: 69-76. Doi: 10.1016/j.foodchem.2017.01.002

Kiekow CJ, Figueiro F, Ditrich F, Vechia D, Pires ENS, Jandrey EHF, Gnoatto SCB, Salbego CG, Battastini AMO, Gosmann G (2016) Quercetin derivative induces cell death in glioma cells by modulating NF-kappa B nuclear translocation and caspase-3 activation. Eur J Pharm Sci 84: 116-122. Doi: 10.1016/j.ejps.2016.01.019

Krajnović T, Kaluderović GN, Wessjohann LA, Mijatović S, Maksimović-Ivanić D (2016) Versatile antitumor potential of isoxanthohumol: enhancement of paclitaxel activity in vivo. Pharmacol Res 105: 62-73. Doi: 10.1016/j.phrs.2016.01.011e

Lim HJ, Nguyen T'TH, Kim NM, Park JS, Jang TS, Kim D (2017) Inhibitory effect of flavonoids against NS2B-NS3 protease of ZIKA virus and their structure activity relationship. Biotechnol Lett 39: 415421. Doi: 10.1007/s10529-016-2261-6

Magalhães PJ, Guido LF, Cruz JM, Barros AA (2007) Analysis of xanthohumol and isoxanthohumol in different hop products by liquid chromatography-diode array detection-electrospray ioniza- tion tandem mass spectrometry. I Chromatogr A 1150: 295-301. Doi: 10.1016/j.chroma.2006.08.019

Miranda CL, Stevens JF, Helmrich A, Henderson MC, Rodriguez RJ, Yang YH, Deinzer ML, Barnes DW, Buhler DR (1999) Antiproliferative and cytotoxic effects of prenylated flavonoids from hops (Humulus lupulus) in human cancer cell lines. Food Chem Toxicol 37: 271-285. Doi: 10.1016/S0278-6915(99)00019-8

Mizobuchi S, Sato Y (1984) A new flavanone with antifungal activity isolated from hops. Agric Biol Chem 48: 2771-2775.

Mukai R, Fujikura Y, Murota K, Uehara M, Minekawa S, Matsui N, Kawamura T, Nemoto H, Terao J (2013) Prenylation enhances quercetin uptake and reduces efflux in Caco-2 cells and enhances tissue accumulation in mice fed long-term. J Nutr 143: 1558-1564. Doi: $10.3945 /$ jn.113

Nevozhay D (2014) Cheburator software for automatically calculating drug inhibitory concentrations from in vitro screening assays. Plos One 9: e106186. Doi: 10.1371/journal.pone.0106186

Saik AYH, Lim YY, Stanslas J, Choo WS (2017) Enzymatic synthesis of quercetin oleate esters using Candida antarctica lipase B. Biotechnol Lett 39: 297-304. Doi: 10.1007/s10529-016-2246-5

Sidoryk K, Jaromin A, Edward JA, Świtalska M, Stefańska J, Couch P, Zagrodzka J, Szczepek W, Peczyńska-Czoch W, Wietrzyk J, Kozubek A, Zarnowski R, Andes DR, Kaczmarek L (2014) Searching for new derivatives of neocryptolepine: synthesis, antiproliferative, antimicrobial and antifungal activities. Eur J Med Chem 78: 304-13. Doi: 10.1016/j.ejmech.2014.03.060

Stevens JF, Taylor AW, Clawson JE, Deinzer ML (1999) Fate of xanthohumol and related prenylflavonoids from hops to beer. I Agric Food Chem 4: 2421-2428. Doi: 10.1021/jf990101k

Stompor M, Potaniec B, Szumny A, Zieliński P, Żołnierczyk A, Anioł M (2013) Microbiological reduction of xanthohumol and 4-methoxychalcone. Przem Chem 92: 574-578

Stompor M, Żarowska B (2016) Antimicrobial activity of xanthohumol and its selected structural analogues. Molecules 21: 608. Doi: 10.3390/ molecules 21050608

Terao J, Mukai R (2014) Prenylation modulates the bioavailability and bioaccumulation of dietary flavonoids. Archiv Biochem Biophys 559: 12-16. Doi: 10.1016/j.abb.2014.04.002

Venturelli S, Burkard M, Biendl M, Lauer UM, Frank J, Busch C (2016) Prenylated chalcones and flavonoids for the prevention and treatment of cancer. Nutrition 32: 1171-1178. Doi: 10.1016/j. nut.2016.03.020

Wesolowska O, Gąsiorowska J, Petrus J, Czarnik-Matusewicz B, Michalak K (2014) Interaction of prenylated chalcones and flavanones from common hop with phosphatidylcholine model membranes. BBA Biomembranes 1838: 173-184. Doi: 10.1016/j.bbamem.2013.09.009

Wilhelm, H, Wessjohann LA (2006) An effecient synthesis of the phytoestrogen 8-prenylnaringenin from xanthohumol by a novel demethylation process. Tetrahedron 62: 6961-6966. Doi: 10.1016/j. tet.2006.04.060

Young WK, Ho YF, Malek SNA (2015) Xanthohumol induces apoptosis and S phase cell cycle arrest in A549 non-small cell lung cancer cells. Pharmacogn Mag 11: S275-S283. Doi: 10.4103/09731296.166069

Zhu ZY, Wang WX, Wang ZQ, Chen LJ, Zhang YJ, Liu XC, Wu SP, Zhang YM (2014) Synthesis and antitumor activity evaluation of chrysin derivatives. Eur J Med Chem; 75: 297-300. Doi: 10.1016/j. ejmech.2013.12.044]. 